\title{
A Formação Pedagógica dos cursos de Licenciatura da UFPB: repensando a prática como componente curricular
}

Fábio do Nascimento Fonsêca

Lenilton Francisco de Assis

RESUMO: O artigo apresenta uma reflexão sobre o papel da Prática como Componente Curricular (PCC) no âmbito da formação pedagógica dos cursos de licenciatura da Universidade Federal da Paraíba (UFPB). Estudo de natureza qualitativa, faz uso de análise documental para avaliar as definições conceituais e normativas da PCC nos currículos das licenciaturas do país e sua regulamentação na UFPB. Na sequência, coloca questões que confrontam os documentos normativos nacionais e institucional, além de apresentar princípios que subsidiam a elaboração de uma proposta de formação pedagógica na qual a PCC adquire nova dimensão e nova organização curricular. Ao final, há um quadro síntese da proposta com a qual se espera fomentar o debate e as revisões dos projetos pedagógicos das licenciaturas da UFPB e de outras instituições onde a PCC também suscita dúvidas e controvérsias.

PALAVRAS-CHAVE: Formação de Professores; Formação Pedagógica; Prática como Componente Curricular.

\section{The Pedagogical Formation of the teacher training courses at the federal university of paraíba: rethinking the practice as curricular component}

\begin{abstract}
The article presents a reflection on the role of Practice as Curricular Component (PCC) within the pedagogical formation of the teacher training courses at the Federal University of Paraíba (UFPB). It is a qualitative study that uses documentary analysis to evaluate the conceptual and normative definitions of the PCC in the curricula of the country's teacher formation courses and its regulation in the UFPB. It then poses questions that confront national and institutional normative documents, as well as presenting principles that support the elaboration of a pedagogical formation proposal in which the PCC acquires a new dimension and new curricular organization. At the end, there is a summary table of the proposal where it is hoped to promote the debate and revisions of the pedagogical projects of the teacher courses of the UFPB and other institutions where the PCC also raises doubts and controversies.
\end{abstract}

KEY WORDS: Teacher training; Pedagogical formation; Practice as Curricular Component. 


\section{autêntica}

DOI https://doi.org/10.31639/rbpfp.v\%vi\%i.196

\section{INTRODUÇÃO}

Em vários países, a formação de professores suscita políticas e reflexões constantes que buscam aprimorar a qualidade da educação que os alunos recebem, especialmente nas escolas públicas (NÓVOA, 1992; GARCÍA, 1999; PIMENTA, 2005; ANDRÉ, 2016). No Brasil, em 2002, o Ministério da Educação e Cultura (MEC) instituiu políticas que alteraram de forma significativa a formação de professores na universidade e ensejaram maior articulação com o campo de atuação profissional - a escola básica. Dentre as modificações exigidas pelas Diretrizes Curriculares Nacionais (Resolução CNE/CP No. 1/2002), estavam a separação entre cursos de bacharelado e licenciatura, a oferta de 400 horas de estágio supervisionado e de 400 horas de Prática como Componente Curricular (PCC). Em 2015, novas DCNs foram divulgadas pelo MEC ampliando o tempo mínimo de formação dos professores (de 2800 para 3200 horas) e ratificando a carga horária definida para o estágio e para a PCC.

Para se adequar à nova legislação (Resolução CNE N. 2/2015), foi deflagrada, na Universidade Federal da Paraíba (UFPB), a atualização dos projetos pedagógicos dos cursos de licenciatura que, logo, tornou necessária a revisão da base curricular que constitui a formação pedagógica. Nesse processo de debate e de construção coletiva do currículo acadêmico, a PCC tem recebido especial atenção, após suscitar críticas e sugestões sobre a concepção e o enquadramento curricular atribuído a esse componente na instituição.

Qual o papel da PCC no currículo das licenciaturas? São componentes da formação específica ou pedagógica? São obrigatórios ou optativos? Quais as diferenças em relação à prática de ensino e ao estágio supervisionado? A quem compete a oferta da PCC? Ao Centro ou Departamento de Educação? Ou também aos Departamentos Específicos que abrigam os cursos de licenciatura?

No intuito de contribuir para o desenvolvimento de uma formação pedagógica mais qualificada e coerente com as demandas contemporâneas para a profissão docente, este estudo de natureza qualitativa faz uso de análise documental para avaliar as definições conceituais e normativas da PCC, a partir de uma breve revisão dos dispositivos legais que a instituíram nos currículos das licenciaturas do país e a regulamentaram na UFPB.

Na sequência, são colocadas questões que confrontam os documentos normativos nacionais e institucional, além de apresentados princípios que subsidiam a elaboração de uma proposta de formação pedagógica na qual a PCC adquire nova dimensão e nova organização curricular.

Ao final, há um quadro síntese dessa proposta com a qual se espera fomentar o debate e as revisões dos projetos pedagógicos das licenciaturas da UFPB e de outras instituições onde a PCC também suscita dúvidas e controvérsias.

\section{PRÁTICA COMO COMPONENTE CURRICULAR: DEFINIÇÕES CONCEITUAIS E NORMATIVAS}

A prática e sua relação com a teoria sempre foi uma preocupação presente nos cursos de licenciatura do Brasil e um problema de difícil solução. Desde a década de 1970, educadores que trabalham na formação de novos professores questionam o modelo de curso 3+1 que oferta, no início, três anos de conteúdos "teóricos" específicos e, no final, um ano de Didática e Prática de Ensino para a aplicação dos conteúdos estudados "na prática".

Nas décadas de 1980 e 1990, as críticas a esse modelo formativo se acentuam tendo como contraponto o consenso de que os professores desempenham uma atividade teórico-prática articulada e indissociável que precisa, assim, ser trabalhada ao longo da formação docente. Segundo Libâneo e Pimenta (1999, p. 267), 


\begin{abstract}
É difícil pensar na possibilidade de educar fora de uma situação concreta e de uma realidade definida. A profissão de professor precisa combinar sistematicamente elementos teóricos com situações práticas reais. Por essa razão, ao se pensar um currículo de formação, a ênfase na prática como atividade formadora aparece, à primeira vista, como exercício formativo para o futuro professor. Entretanto, em termos mais amplos, é um dos aspectos centrais na formação do professor, em razão do que traz consequências decisivas para a formação profissional.
\end{abstract}

Mas de que prática se está falando? Da Prática de Ensino que tem sido substituída pelo Estágio Supervisionado? Ou da Prática como Componente Curricular que se tornou obrigatória nas últimas décadas? Afinal, qual a diferença entre elas na legislação que dispõe sobre a formação de professores no país?

Até a promulgação da Lei de Diretrizes e Bases da Educação Nacional, LDBEN N. 9.394/1996 (BRASIL, 1996), o estágio, nos cursos de licenciatura, era designado como "Prática de Ensino sob a forma de Estagio Supervisionado". Noutras palavras, a prática de ensino era concebida como estágio curricular supervisionado, e a única alteração significativa, a partir da LDBEN, foi a ampliação da carga horária para trezentas horas.

A definição de "prática de ensino", nos termos do artigo 65 da LDBEN (BRASIL, 1996), suscitou, todavia, da parte das instituições formadoras, incompreensão acerca do alcance do seu significado. O que ensejou a necessidade de manifestação do Conselho Nacional de Educação (CNE), através de sua Câmara de Educação Superior, com o Parecer CNE/CES 744/97, para definir que a prática de ensino:

Constitui o espaço por excelência da vinculação entre formação teórica e início da vivência profissional, supervisionada pela instituição formadora. A prática de ensino consiste, pois, em uma das oportunidades nas quais o estudante-docente se defronta com os problemas concretos do processo de ensino-aprendizagem e da dinâmica própria do espaço escolar (BRASIL, 1997, p. 1).

Posteriormente, o Parecer CNE/CP N. 9/2001 (BRASIL, 2001a) referendou tal compreensão, ao indicar que a prática deverá ocorrer ao longo do processo formativo no curso de graduação, já a partir do primeiro ano, como uma ação integrada e que não se limita apenas ao estágio supervisionado.

O mencionado parecer, que tratou das Diretrizes Curriculares Nacionais para a Formação de Professores da Educação Básica - em nível superior, em cursos de licenciatura, de graduação plena -, ao discutir aspectos problemáticos e desafios a serem enfrentados no campo da formação docente, destacou, entre outros, a permanência de uma concepção restritiva de prática, alicerçada numa visão dicotômica que segmenta o curso em dois polos isolados entre si: um que caracteriza o trabalho na sala de aula e outro que caracteriza as atividades de estágio.

No primeiro polo, como expressão de uma visão aplicacionista das teorias no processo formativo, há uma supervalorização dos conhecimentos teóricos e acadêmicos, com o consequente desprezo das práticas como fonte importante de conteúdos para a formação. No polo oposto, se expressa uma visão ativista da prática, sustentada na supervalorização do fazer pedagógico, que desdenha da "dimensão teórica dos conhecimentos como instrumento de seleção e análise contextual das práticas" (BRASIL, 2001a, p. 22-23).

Desse modo, a formação em sala de aula se caracterizaria pela apresentação de teorias prescritivas e analíticas, cabendo aos estágios, num momento posterior, a tarefa de colocar tais conhecimentos em prática. Para o enfrentamento da questão, o parecer propunha uma visão de prática que se configuraria "mais como componente curricular", entendendo que o conhecimento se faz presente tanto na reflexão sobre a atividade 


\section{autêntica}

DOI https://doi.org/10.31639/rbpfp.v\%vi\%i.196

profissional em sala de aula, como durante a realização dos estágios, quando a atividade profissional é exercitada. O referido parecer indicava a superação da ideia de que a sala de aula é o âmbito de tratamento da teoria, enquanto ao estágio cabe se encarregar da prática.

Ainda em 2001, O CNE, por meio do Conselho Pleno, aprovou o Parecer CNE/CP 21/2001 (BRASIL, 2001 b), que não chegou a ser homologado. Este parecer estabelecia a duração e a carga-horária dos cursos de formação de professores da educação básica, propondo o cumprimento de, pelo menos, 2.800 horas. Dentro dessas, foram incluídas 400 horas de prática de ensino, que deveriam ser vivenciadas ao longo do curso; e 400 horas de estágio supervisionado, sob forma concentrada, ao final do curso.

Também no mesmo ano, o Parecer CNE/CP N. 27/2001(BRASIL, 2001c) apresentou definições acerca do estágio supervisionado, dentre as quais a indicação de que o mesmo deveria ser vivenciado em escolas de educação básica e ao longo do curso de formação, de maneira a abordar as diferentes dimensões de atuação profissional, contempladas no Projeto Político-Pedagógico. Ainda em 2001, no Parecer CNE/CP N. 28/2001 (BRASIL, 2001d), o CNE procurou explicitar a compreensão assumida no que se refere à relação teoria e prática:

[...] há que se distinguir, de um lado, a prática como componente curricular e, de outro, a prática de ensino e o estágio obrigatório definidos em lei. A primeira é mais abrangente: contempla os dispositivos legais e vai além deles. [...] Esta correlação teoria e prática é um movimento contínuo entre saber e fazer na busca de significados na gestão, administração e resolução de situações próprias do ambiente da educação escolar (BRASIL, 2001d, p. 9).

No início do ano de 2002, o CNE aprovou a Resolução CNE/CP N. 1/2002 (BRASIL, 2002a), que estabeleceu as Diretrizes Curriculares Nacionais para a Formação de Professores da Educação Básica, com base nos Pareceres CNE/CP 9/2001 (BRASIL, 2001a) e 27/2001 (BRASIL, 2001c). Nas diretrizes aprovadas pelo CNE, a prática apareceu não mais como algo restrito ao estágio supervisionado, mas como dimensão que deveria estar presente desde o início do curso. O estágio supervisionado, por sua vez, passou a ser considerado um espaço interdisciplinar de formação, cujo propósito deve ser o de favorecer um maior conhecimento acerca da realidade profissional, a partir de um processo de estudo, pesquisa, análise, problematização, teorização, reflexão, proposição de alternativas, intervenção e redimensionamento da ação.

No mesmo ano de 2002, com a finalidade de regulamentar a duração e a carga horária dos cursos de licenciatura, o CNE aprovou, em fevereiro, a Resolução CNE/CP N. 2/2002 (BRASIL, 2002b), com fundamento no Artigo 12 da Resolução CNE/CP N. 1/2002 (BRASIL, 2002a) e no Parecer CNE/CP N. 28/2001 (BRASIL, 2001d), estabelecendo a carga horária de 400 horas para a prática como componente curricular, a serem vivenciadas ao longo do curso, e, também, 400 horas de carga horária para o estágio curricular supervisionado, a partir do início da segunda metade do curso.

A Prática como Componente Curricular, de acordo com a Resolução No. 1/2002, deveria ser trabalhada no interior das áreas ou das disciplinas que constituíssem os componentes curriculares da formação docente e não somente nas disciplinas de cunho pedagógico. Noutras palavras, todos os componentes, devem apresentar uma dimensão prática (BARBOSA, 2014, p. 5).

Não obstante o processo de construção de definições acerca da prática como componente curricular e do estágio supervisionado, nos sucessivos pareceres aprovados pelo CNE, entre meados da década de 1990 
e início dos anos de 2000, quando foram aprovadas as primeiras Diretrizes Curriculares Nacionais para a formação de professores da educação básica, permaneciam, ainda, dúvidas com respeito à distinção entre o estágio supervisionado e a PCC. Tais dúvidas envolviam, sobretudo, as instituições formadoras e os cursos de licenciatura, nos processos de adequação de seus currículos às novas orientações emanadas das Diretrizes. A permanência destas dúvidas ensejou manifestações de membros do CNE que, a exemplo de Weber (2002), buscaram oferecer contribuições no esforço de interpretação das orientações normativas. Para Weber, a PCC não tem o mesmo significado que prática de ensino. De acordo com a então conselheira do CNE:

\footnotetext{
No que se refere à formação de professores, a necessária vinculação entre teoria e prática expressa, entre outros aspectos, por intermédio da definição da prática como componente curricular, é quase sempre interpretada como sendo equivalente à prática de ensino. Trata-se de uma interpretação reducionista por não incluir como prática outras atividades pedagógicas relevantes ao fazer escolar (WEBER, 2002, p. 95).
}

O próprio Conselho Nacional de Educação, à época, se pronunciou acerca da matéria, com o propósito de elucidar a questão em definitivo, o fazendo através do Parecer CNE/CES No. 15/2005(BRASIL, 2005), no qual se estabeleceu que:

[...] a prática como componente curricular é o conjunto de atividades formativas que proporcionam experiências de aplicação de conhecimentos ou de desenvolvimento de procedimentos próprios ao exercício da docência [...] As atividades caracterizadas como prática como componente curricular podem ser desenvolvidas como núcleo ou como parte de disciplinas ou de outras atividades formativas [...] As disciplinas relacionadas com a educação que incluem atividades de caráter prático podem ser computadas na carga horária classificada como prática como componente curricular, mas o mesmo não ocorre com as disciplinas relacionadas aos conhecimentos técnico-científicos próprios da área do conhecimento para a qual se faz a formação (BRASIL, 2005, p. 3).

Após mais de dez anos de vigência das primeiras diretrizes curriculares nacionais para a formação de professores, o CNE aprovou, em julho de 2015, através do Parecer CNE/CP N. 2/2015 (BRASIL, 2015a) e da Resolução CNE/CP Nº. 02/2015(BRASIL, 2015b), as novas diretrizes para a formação inicial e continuada de professores para a educação básica. As diretrizes recém-aprovadas estabelecem, em seu artigo 13, que os cursos de formação inicial, em nível superior, deverão ter carga horária mínima de 3.200 horas de efetivo trabalho acadêmico. Quanto à duração, os cursos de formação inicial distribuirão as 3.200 horas em, no mínimo, oito semestres ou quatro anos, da seguinte forma:

- 400 horas de prática como componente curricular, distribuídas ao longo do processo formativo;

- 400 horas dedicadas ao estágio supervisionado, na área de formação e atuação na educação básica, contemplando também outras áreas específicas, se for o caso, conforme o projeto de curso da instituição;

- Pelo menos 2.200 horas dedicadas às atividades formativas estruturadas pelos núcleos definidos nos incisos I e II, do artigo 12;

- 200 horas de atividades teórico-práticas de aprofundamento em áreas especifica de interesse dos estudantes, conforme núcleo definido no inciso III do artigo 12

Também foi mantida, para a prática como componente curricular e para o estágio supervisionado, a mesma carga horária anteriormente definida pela Resolução CNE/CP Nº. 2/2002, ou seja, 400 horas para cada um dos componentes. 


\section{autêntica}

DOI https://doi.org/10.31639/rbpfp.v\%vi\%i.196

\section{A PRÁTICA COMO COMPONENTE CURRICULAR NO ÂMBITO DA UFPB}

Ao introduzir a noção de prática como componente curricular no âmbito da UFPB (ESCARIÃO; NÁDER, 2004), a Resolução Nº. 04/2004, do Conselho Superior de Ensino, Pesquisa e Extensão (CONSEPE), em seu Artigo $3^{\circ}$, define a prática curricular como "o conjunto de atividades curriculares teóricas e práticas que tem como objeto de trabalho os elementos comuns presentes nas práticas profissionais dos docentes da Educação Básica" (UFPB, 2004, p. 2). Vê-se, pois, na definição construída no âmbito da UFPB, a incorporação, de forma pioneira no âmbito normativo da instituição, da compreensão estabelecida no debate nacional que buscou afirmar a complementaridade e o equilíbrio que deveriam nortear a relação entre teoria e prática, compreendendo esta última como dimensão que vai além do estágio supervisionado e que deve estar lastreada na reflexão necessária sobre o exercício do trabalho docente.

A referida resolução atribuiu à PCC uma carga horária mínima de 420 horas-aula1, correspondente a 28 créditos, cursados ao longo de todo o curso de licenciatura e distribuídos entre os conteúdos dos seguintes eixos temáticos de natureza formativa:

- Pressupostos Antropo-filosóficos, Sócio-históricos e Psicológicos;

- Pressupostos Sócio-políticos e Pedagógicos;

- Pressupostos Didático-metodológicos e Sócio-educativo.

Posteriormente, a Resolução CONSEPE/UFPB №. 46/2012 (UFPB, 2012) reestruturou a Resolução №. 04/2004, mantendo a carga horária mínima de 28 créditos, correspondentes a 420 horas-aula, e redistribuindo, todavia, os conteúdos formativos da PCC em disciplinas obrigatórias e optativas. Assim, os conteúdos curriculares obrigatórios da PCC, totalizando 20 créditos, equivalentes a 300 horas-aula, foram distribuídos em eixos temáticos, de acordo com as especificações abaixo, sendo desdobrados em disciplinas conforme especificado no Anexo da mencionada Resolução (artigo $4^{\circ}$, parágrafo $1^{\circ}$ ):

- Eixo I: Pressupostos Antropo-filosóficos, Sócio-históricos e Psicológicos - 12 créditos, correspondendo a 180 horas-aula;

- Eixo II: Pressupostos Sócio-políticos e Pedagógicos - 04 créditos, correspondendo a 60 horas-aula;

- Eixo III: Pressupostos Didático-metodológicos e Sócio-educativo - 04 créditos, correspondendo a 60 horas-aula.

Os conteúdos curriculares optativos da PCC, por sua vez totalizando 08 créditos, equivalentes a 120 horas-aula, deveriam ser escolhidos dentro de um conjunto de disciplinas também elencadas no anexo da mesma resolução.

Em 2015, a UFPB buscou consolidar, num único dispositivo, o conjunto de normas para a graduação existente na instituição. A Resolução CONSEPE/UFPB N. 16/2015 instituiu o Regulamento dos Cursos Regulares de Graduação da UFPB, incorporando e mantendo as definições constantes nas Resoluções No. 04/2004 e Nº. 46/2002 do CONSEPE/UFPB. Assim, na modalidade licenciatura, nos termos do regulamento, devem ser incluídos os conteúdos curriculares referentes à PCC, com duração mínima de 420 horas, e os estágios supervisionados, com 405 horas, devendo ser ofertados ao longo do curso e regulamentados pelos Colegiados de Curso (artigo 21, parágrafo $3^{\circ}$, inciso II). 
Nos termos do artigo 31 do Regulamento dos Cursos de Graduação da UFPB, a base curricular para os cursos de licenciatura manteve-se, desse modo, constituída pela prática curricular e pelo estágio supervisionado de ensino, os quais devem ser oferecidos ao longo do curso, como observação e interlocução com a realidade, como aprofundamento teórico-metodológico da práxis docente e como iniciação e intervenção profissional acompanhada.

No tocante ao significado atribuído à PCC, o regulamento acima referido a define, em seu artigo 32, como "o conjunto de atividades curriculares teóricas e práticas que tem como objeto de trabalho os elementos comuns presentes nas práticas profissionais dos docentes da Educação Básica", reafirmando a compreensão estabelecida desde as Resoluções Nº. 04/2004 e N. 46/2002 do CONSEPE/UFPB.

Com respeito à distribuição dos conteúdos e da carga horária da PCC, o Regulamento dos Cursos de Graduação da UFPB reproduziu o disposto na Resolução CONSEPE/UFPB Nº. 04/2004, definindo os conteúdos curriculares da PCC entre obrigatórios e optativos. Os conteúdos obrigatórios, totalizando 20 créditos, equivalentes à 300 horas-aula, foram distribuídos em eixos temáticos definidos pela Pró-Reitoria de Graduação (PRG) e já supramencionados.

A carga horária restante, para compor as 420 horas da PCC, foi definida, no mesmo Regulamento, em torno de conteúdos curriculares optativos que totalizam 08 créditos, equivalentes a 120 horas-aula, devendo ser escolhidos entre os componentes curriculares a serem definidos pela Pró-Reitoria de Graduação (PRG), em portaria específica para este fim.

\section{OBSERVAÇÕES E QUESTÕES}

Com a aprovação das novas Diretrizes Curriculares Nacionais para a Formação Inicial e Continuada de Professores para a Educação Básica (Resolução CNE Nº. 02/2015), deu-se, no âmbito da UFPB, o processo de revisão e adequação, tanto do Regulamento dos Cursos de Graduação quanto dos Projetos Pedagógicos dos Cursos de Licenciatura.

Nesta discussão, ao confrontar-se as definições do Regulamento da Graduação da UFPB com as bases normativas instituídas pela Resolução CNE/CP №. 02/2015, verificou-se, a princípio, as diferenças no tocante à carga horária estabelecida para o estágio supervisionado e para prática como componente curricular, nos dois documentos. O Regulamento dos Cursos de Graduação da UFPB (Resolução CONSEPE/UFPB N. 16/2015) apresenta uma carga maior (420 horas para a prática como componente curricular e 405 horas para o estágio supervisionado) que aquela proposta nas novas Diretrizes (400 horas para a prática como componente curricular 400 horas para o estágio supervisionado). Neste aspecto, cumpriu-se a necessidade de esclarecer que as Diretrizes estabelecem sempre a carga horária mínima para estes componentes, não impedindo, portanto, que os cursos, na composição da carga horária apresentada em seus PPC's, ultrapassem o mínimo estabelecido nas Diretrizes.

Para além do aspecto da carga horária, a primeira questão de fundo a ser tomada em consideração, na discussão acerca da adequação do Regulamento da Graduação e dos Projetos Pedagógicos das Licenciaturas na UFPB, girou em torno do próprio conceito de Prática como Componente Curricular (PCC). Neste particular, observou-se que as atuais Diretrizes não acrescentam aspectos novos na definição da PCC, mantendo-se, portanto, as orientações já estabelecidas no Artigo 12 da resolução que Ihe antecedeu (Resolução CNE/ $C P N^{\circ}$. 1/2002). Tais orientações indicam, no parágrafo $3^{\circ}$, que "no interior das áreas ou das disciplinas que 


\section{autêntica}

DOI https://doi.org/10.31639/rbpfp.v\%vi\%i.196

constituírem os componentes curriculares de formação, e não apenas nas disciplinas pedagógicas, todas terão a sua dimensão prática" (BRASIL, 2002, p. 5). Noutras palavras, ainda que o Parecer CNE №. 15/2005 tenha admitido que "as disciplinas relacionadas com a educação que incluem atividades de caráter prático podem ser computadas na carga horária classificada como prática como componente curriculares", os termos da Resolução CNE/CP Nº 01/2002 deixam claro que a prática como componente curricular não pode se limitar às mesmas.

Por outra parte, o parecer CNE $N^{\circ}$. 15/2005 afirma que isso não ocorre com as disciplinas relacionadas aos conhecimentos técnico-científicos próprios da área do conhecimento para a qual se faz a formação", as quais não devem compor a Prática como Componente Curricular.

Ora, as definições do Regulamento da Graduação (Resolução CONSEPE/UFPB №. 16/2015) que incorporam as definições anteriores das Resoluções CONSEPE/UFPB Nº. 04/2004 e 46/2012 restringem, todavia, a prática curricular às disciplinas de natureza pedagógica. Tal configuração, conforme indica investigação realizada por Barbosa (2014), envolvendo cursos de licenciatura de instituições de ensino superior da Paraíba, incluída a UFPB, contraria as orientações normativas vigentes, as quais, embora admitam a presença de disciplinas pedagógicas na composição da prática como componente curricular, estabelece que tal composição não pode se limitar a estas disciplinas.

Ao lado dessa evidência, no processo de discussão acerca da revisão e adequação do Regulamento dos Cursos de Graduação e dos projetos pedagógicos dos cursos de licenciatura, surgiram outros questionamentos, na interlocução com Coordenadores de Cursos, em reuniões do Fórum das Licenciaturas da UFPB ou mesmo em visitas aos Coordenadores, Chefes de Departamento e Núcleos Docentes Estruturantes (NDE's), em diferentes Centros de Ensino da instituição. Tais questionamentos gravitaram em torno de queixas em relação à atual configuração da PCC no âmbito da UFPB, bem como eventuais reivindicações de flexibilização desta configuração, de modo que os cursos pudessem participar da definição do que deveria ser a PCC ou, ainda, assumir responsabilidades na sua formulação e na indicação de formas de oferta da mesma.

Deste debate, surgiram, então, as seguintes questões: como construir um processo de redefinição da prática como componente curricular no âmbito da UFPB, considerando que a mesma não pode se restringir às disciplinas pedagógicas, e, de outro lado, as disciplinas técnico-científicas não podem compor tal prática? Como facultar aos cursos a autonomia para definir, nos seus colegiados, suas formas de conceber e ofertar a PCC, sem prejuízo ou sacrifício dos componentes pedagógicos da formação docente, atualmente envolvidos na definição de prática curricular vigente na UFPB?

Nesta direção, a busca de solução para estas questões indicou as próprias Diretrizes recém-aprovadas (Resolução CNE Nº. 02/2015) como referência para a construção de respostas. As novas Diretrizes, em seu artigo 12, estabelecem, na definição dos núcleos de sua composição curricular, que os conhecimentos do campo educacional, seus fundamentos e metodologias, bem como das diversas realidades educacionais fazem parte do Núcleo de estudos de formação geral, das áreas específicas e interdisciplinares (Inciso I). De igual modo, inclui os conteúdos pedagógicos, ao lado dos específicos, no Núcleo de aprofundamento e diversificação de estudos das áreas de atuação profissional (Inciso II). Desse modo, é possível conceber uma base curricular que assegure o lugar dos conhecimentos educacionais e pedagógicos nos projetos dos cursos de licenciatura, sem que os mesmos estejam restritos à PCC e nem esta limitada à formação pedagógica ofertada pelo Centro ou Departamentos de Educação. 


\section{POSSIBILIDADES E PROPOSTAS}

No esforço para construir respostas às questões suscitadas, bem como considerando, ainda, as possibilidades indicadas nas novas diretrizes para a formação de professores, pretende-se, aqui, o exame das configurações existentes como ponto de partida para a indicação de propostas para a definição da PCC nos currículos dos cursos de licenciatura da UFPB. Nesta direção, contribuiu o já mencionado estudo de Barbosa (2014), que levantou o modo como a PCC foi implantada e ofertada em instituições da Paraíba (UFPB e UFCGUniversidade Federal de Campina Grande), analisando também a experiência de outras instituições. Nesta análise, Barbosa (2014) identificou pelo menos quatro situações distintas em termos da oferta da prática como componente curricular:

a) quando a PCC é integrada com as disciplinas pedagógicas do curso;

b) quando a PCC é trabalhada nas disciplinas específicas do curso;

c) quando a PCC é trabalhada tanto nas disciplinas pedagógicas quanto nas disciplinas específicas do curso:

d) quando na matriz curricular dos cursos foram criadas disciplinas próprias para a PCC ser trabalhada, essa normalmente recebe o nome de "Prática de Ensino" (BARBOSA, 2014, p. 9).

Considerando as várias situações apontadas por Barbosa (2014), assim como as balizas estabelecidas pelas Diretrizes de 2002 e 2015, pelo Parecer CNE No. 15/2015 e, ainda o contexto específico da UFPB, com o Regulamento dos Cursos de Graduação, a revisão da definição da PCC, no marco normativo para a oferta das licenciaturas na UFPB, poderia assumir as seguintes configurações:

- A manutenção das definições atuais, com a PCC constituída pelas disciplinas pedagógicas (o que, como já foi assinalado neste texto, contraria o disposto na Resolução CNE/CP Nº. 2/2002 e que não foi alterado pela Resolução CNE/CP Nº. 2/2015);

- O deslocamento das disciplinas pedagógicas para outros espaços dos eixos curriculares, ficando a PCC a ser trabalhada nas disciplinas específicas do curso (o que, por sua vez, contraria o que dispõe o Parecer CNE N. 15/2015):

- A flexibilização da definição atual, mantendo-se a distribuição das 300 horas de componentes obrigatórios da PCC, flexibilizando-se as 120 horas de componentes optativos, cuja definição ficaria a cargo de cada curso de licenciatura (o que não deixaria de ferir, em um ou outro aspecto, disposições das normas mencionadas acima);

- Por fim, a criação, nos cursos, de espaço próprio para a PCC, com o deslocamento das disciplinas pedagógicas para outros eixos curriculares obrigatórios (o que significaria a criação de componentes curriculares próprios para a PCC) e, quando necessário, com a participação de disciplinas pedagógicas na composição da carga-horária da prática como componente curricular, porém sem se limitar a estas disciplinas. Assim, o Departamento Específico pode oferecer sozinho a PCC e em conjunto com o Centro ou Departamentos de Educação, além de outros departamentos da universidade.

Dentre as situações apontadas acima, a última alternativa pareceu expressar uma resposta mais adequada, tanto no que toca ao atendimento às prescrições normativas vigentes quanto na perspectiva de possibilitar a definição, por parte dos cursos, dos elementos que comporiam a PCC, assegurando, por outro lado, espaço próprio para o tratamento dos componentes de natureza pedagógica. Essa alternativa também se adequa à mudança vivenciada na oferta da formação pedagógica na UFPB que, antes restrita ao Centro ou 


\section{autêntica}

DOI https://doi.org/10.31639/rbpfp.v\%vi\%i.196

Departamentos de Educação, hoje, gradativamente, tem sido compartilhada pelos Departamentos Específicos com a contratação de professores especialistas em ensino. E essa é uma consequência da separação dos cursos de licenciatura e bacharelado que foi uma das exigências da Resolução CNE/CP N. 1/2002.

Porém, essa mudança tem sido gradual e com realidades muito díspares entre as licenciaturas da UFPB. Há cursos que contrataram especialistas em ensino e já assumiram a responsabilidade pela oferta dos estágios supervisionados e de outros componentes voltados à formação pedagógica. Mas, há outros, que sequer fizeram a revisão dos currículos exigida pelas DCNs de 2002 e ainda reservam a formação pedagógica exclusivamente ao Centro ou Departamentos de Educação. Também, há aqueles cuja oferta já tem sido compartilhada entre o Departamento Específico e o Centro ou Departamentos de Educação.

Assim, como alternativa para essa diversidade de situações, propõe-se que a prática como componente curricular deva ser trabalhada ao longo do currículo, com a criação de componentes curriculares próprios pelos Departamentos Específicos que podem assumir a responsabilidade total e, porventura, compartilhada com o Centro ou Departamentos de Educação.

Vale lembrar que, conforme definição do Parecer CNE/CP, N. 28, de 2 de outubro de 2001, a PCC é uma "prática que produz algo no âmbito do ensino" e, portanto, pode originar o conhecimento e a análise de situações pedagógicas por meio de componentes integradores de conteúdos específicos e interdisciplinares que problematizem situações de ensino e fomentem a relação teoria-prática, universidade-escola, sem depender, necessariamente, da observação direta ou da permanência no espaço escolar - o que caracteriza o estágio supervisionado e o diferencia da PCC.

Desde o ingresso dos alunos no curso, é preciso integrar os conteúdos das disciplinas em situações da prática que coloquem problemas aos futuros professores e lhes possibilitem experimentar soluções. Isso significa ter a prática, ao longo do curso, como referente direto para contrastar seus estudos e formar seus próprios conhecimentos e convicções a respeito. Ou seja, os alunos precisam conhecer o mais cedo possível os sujeitos e as situações com que irão trabalhar. Significa tomar a prática profissional como instância permanente e sistemática na aprendizagem do futuro professor e como referência para a organização curricular (LIBÂNEO; PIMENTA, 1999, p. 267-8).

Essa nova dimensão da PCC, na UFPB, oportuniza aos cursos de licenciatura participarem também da formação pedagógica e repensarem os conteúdos específicos tendo como referência a prática escolar. Tais componentes podem ser ofertados em formatos flexíveis, como Disciplina, Seminário ou Oficina².

Espera-se, por fim, que os elementos trazidos pelo presente texto contribuam para uma definição que preserve a Prática como Componente Curricular como espaço de reflexão coletiva das questões relacionadas ao exercício da prática educativa, envolvendo a especificidade de cada área de atuação e preservando, ao mesmo tempo, a necessária base de formação pedagógica para o trabalho docente.

\section{PRINCÍPIOS FORMATIVOS}

Em consonância com a legislação vigente e com a reconfiguração apresentada para a Prática como Componente Curricular, essa proposta de revisão da Formação Pedagógica dos Cursos de Licenciatura da UFPB tem como objetivo melhorar a formação do professor para atuar na Educação Básica. Para tanto, baseia-se nos seguintes princípios formativos que devem nortear a elaboração dos projetos pedagógicos dos cursos: 


\section{autêntica}

DOI https://doi.org/10.31639/rbpfp.v\%vi\%i.196

\section{ARTICULAÇÃO ENTRE TEORIA E PRÁTICA}

Inspira-se na compreensão de que a teoria e a prática não podem ser trabalhadas de forma dissociada no currículo da licenciatura e que não se deve privilegiar, primeiro, a aquisição de conhecimento (teoria) para a sua posterior aplicação (prática). Teoria e prática constituem os fundamentos da prática educativa e, portanto, devem ser trabalhadas de maneira articulada em todos os componentes curriculares e ao longo da formação.

\section{APROXIMAÇÃO ENTRE UNIVERSIDADE E ESCOLA PÚBLICA}

Ao longo do processo formativo, deve-se promover a aproximação, a interação e o diálogo entre a universidade e a escola pública, além de outros espaços educativos escolares e não escolares que são importantes para o conhecimento e para a inserção profissional dos estudantes. É necessário reconhecer e valorizar as redes públicas de educação básica como espaços para parcerias essenciais à formação docente.

\section{INTERDISCIPLINARIDADE, AUTONOMIA E FLEXIBILIDADE CURRICULAR}

Deve-se valorizar a integração de estudos e de componentes curriculares que promovam a articulação de saberes específicos, pedagógicos e da experiência profissional. A fragmentação de saberes não favorece o avanço da profissionalização docente. É preciso também dar oportunidade para os estudantes desenvolverem a autonomia e definirem parte de seu percurso formativo na estrutura curricular dos projetos pedagógicos dos cursos.

\section{PLURALISMO DE IDEIAS E DE CONCEPÇÕES PEDAGÓGICAS}

Concepções existem para ampliar e possibilitar análises e compreensões sobre um assunto. O pluralismo de ideias é base das ciências humanas e da educação. As concepções pedagógicas, seus fundamentos e inter-relações são fundamentais para a autonomia e a emancipação do profissional docente.

\section{FORTALECIMENTO DA IDENTIDADE E DA PROFISSIONALIZAÇÃO DOCENTE}

É preciso fortalecer a identidade e a profissionalização docente desde o início da formação, não separando os conhecimentos específicos da prática profissional, de modo que os futuros professores reflitam continuamente sobre sua condição de educador e se sintam valorizados e seguros quanto às condições ofertadas para o seu ofício.

\section{VALORIZAÇÃO DA PESQUISA E DA SUA ARTICULAÇÃO COM O ENSINO E A EXTENSÃO}

A formação do professor-pesquisador ultrapassa a ideia equivocada do professor como reprodutor e executor de conhecimentos. A participação em projetos de ensino, pesquisa e extensão estimula a formulação de problemas, a seleção de métodos e instrumentos que favorecem também a investigação e a reflexão crítica sobre e ação docente.

\section{PROPOSTA DE BASE CURRICULAR PARA A FORMAÇÃO PEDAGÓGICA}

A base curricular proposta para a formação pedagógica incorpora os princípios supracitados e compreende três dimensões, a saber: 1. Geral (de natureza multidisciplinar da Educação); 2. Específica (referente ao estágio supervisionado); 3. Específica e Interdisciplinar (relativa à prática como componente curricular). Seguindo estas dimensões e suas respectivas subdivisões, correlacionamos os Núcleos definidos no Art. 


\section{autêntica}

DOI https://doi.org/10.31639/rbpfp.v\%vi\%i.196

12 da Resolução CNE N. 02/2015 com os Conteúdos definidos no Art. 20 do Regulamento dos Cursos de Graduação da UFPB (Resolução CONSEPE/UFPB Nº. 16/2015), estabelecendo a seguinte correspondência no quadro síntese abaixo:

QUADRO SÍNTESE DA BASE CURRICULAR PARA A FORMAÇÃO PEDAGÓGICA NA UFPB

\begin{tabular}{|c|c|c|c|c|c|}
\hline DIMENSÃO & $\begin{array}{c}\text { NÚCLEO } \\
\text { (Res. CNE No. } \\
\text { 02/2015, Art. 12) }\end{array}$ & $\begin{array}{c}\text { EIXO } \\
\text { CURRICULAR } \\
\text { (Res. UFPB No. } \\
\text { 16/2015) }\end{array}$ & $\begin{array}{l}\text { EIXO TEMÁTICO } \\
\text { (Res. UFPB No. } \\
16 / 2015)\end{array}$ & $\begin{array}{l}\text { COMPONENTE } \\
\text { CURRICULAR } \\
\text { (Disciplina) }\end{array}$ & $\begin{array}{l}\text { UNIDADE } \\
\text { RESP* }\end{array}$ \\
\hline \multirow[t]{3}{*}{$\begin{array}{l}\text { Multidisciplinar } \\
\text { da Educação }\end{array}$} & \multirow{3}{*}{$\begin{array}{c}\text { I - Núcleo de } \\
\text { estudos de } \\
\text { formação geral, } \\
\text { das áreas } \\
\text { específicas e } \\
\text { interdisciplinares, } \\
\text { e do campo } \\
\text { educacional }\end{array}$} & \multirow[t]{3}{*}{$\begin{array}{l}\text { Conteúdos } \\
\text { básicos } \\
\text { profissionais }\end{array}$} & $\begin{array}{l}\text { I: Pressupostos } \\
\text { Antropo-filosóficos, } \\
\text { Sócio-históricos e } \\
\text { Psicológicos } \\
\text { (12 créditos) }\end{array}$ & $\begin{array}{c}\text { Fund. } \\
\text { Antropo-filosóficos } \\
\text { da Educação } \\
\text { (60 h/a) } \\
\text { Fund. } \\
\text { Sócio-históricos } \\
\text { da Educação } \\
\text { (60 h/a) } \\
\text { Fund. Psicológicos } \\
\text { da Educação } \\
\text { (60 h/a) }\end{array}$ & DFE/CE \\
\hline & & & $\begin{array}{l}\text { II: Pressupostos } \\
\text { Sócio-políticos } \\
\text { e Pedagógicos } \\
\text { (04 créditos) }\end{array}$ & $\begin{array}{c}\text { Política e Gestão } \\
\text { da Educação } \\
\text { (60 h/a) }\end{array}$ & DHP/CE \\
\hline & & & $\begin{array}{l}\text { III: Pressupostos } \\
\text { Didático- } \\
\text { metodológicos e } \\
\text { Sócio-educativos } \\
\text { (04 créditos) }\end{array}$ & $\begin{array}{l}\text { Didática } \\
\text { (60 h/a) }\end{array}$ & DME/CE \\
\hline Total & & & 20 Créditos & 300 h/a & \\
\hline
\end{tabular}




\begin{tabular}{|c|c|c|c|c|c|}
\hline DIMENSÃO & $\begin{array}{c}\text { NÚCLEO } \\
\text { (Res. CNE No. } \\
\text { 02/2015, Art. } \\
\text { 12) }\end{array}$ & 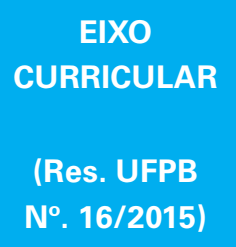 & $\begin{array}{l}\text { EIXO TEMÁTICO } \\
\text { (Res. UFPB No. } \\
\text { 16/2015) }\end{array}$ & $\begin{array}{l}\text { COMPONENTE } \\
\text { CURRICULAR } \\
\text { (Atividade Coletiva) }\end{array}$ & $\begin{array}{l}\text { UNIDADE } \\
\text { RESP** }\end{array}$ \\
\hline $\begin{array}{c}\text { ESPECÍFICA } \\
\text { Estágio } \\
\text { Supervisionado }\end{array}$ & $\begin{array}{c}\text { I - Núcleo } \\
\text { de estudos } \\
\text { de formação } \\
\text { geral, das áreas } \\
\text { específicas e } \\
\text { interdisciplina- } \\
\text { res, e do campo } \\
\text { educacional }\end{array}$ & $\begin{array}{l}\text { Conteúdos } \\
\text { básicos } \\
\text { profissionais }\end{array}$ & $\begin{array}{l}\text { Estágio Superv. } \\
\text { (28 créditos) }\end{array}$ & $\begin{array}{l}\text { Estágio Superv. de } \\
\text { Ensino I (105 h/a) } \\
\text { Estágio Superv. de } \\
\text { Ensino II (105 h/a) } \\
\text { Estágio Superv. de } \\
\text { Ensino III (105 h/a) } \\
\text { Estágio Superv. de } \\
\text { Ensino IV (105 h/a) }\end{array}$ & $\begin{array}{c}\text { Depart. } \\
\text { Específico } \\
\text { ou DME/CE }\end{array}$ \\
\hline Total & & & 28 Créditos & $420 \mathrm{~h} / \mathrm{a}$ & \\
\hline
\end{tabular}

\begin{tabular}{|c|c|c|c|c|c|}
\hline DIMENSÃO & $\begin{array}{l}\text { NÚCLEO } \\
\text { (Res. CNE Nº. } \\
\text { 02/2015, Art. 12) }\end{array}$ & $\begin{array}{c}\text { EIXO } \\
\text { CURRICULAR } \\
\text { (Res. UFPB No. } \\
16 / 2015\end{array}$ & $\begin{array}{c}\text { EIXO } \\
\text { TEMÁTICO } \\
\text { (Res. UFPB Nº } \\
\text { 16/2015) }\end{array}$ & $\begin{array}{l}\text { COMPONENTE } \\
\text { CURRICULAR }\end{array}$ & $\begin{array}{l}\text { UNIDADE } \\
\text { RESP** }\end{array}$ \\
\hline $\begin{array}{c}\text { ESPECÍFICA } \\
\text { Prática como } \\
\text { Componente } \\
\text { Curricular - PCC }\end{array}$ & \multirow{2}{*}{$\begin{array}{c}\text { II - Núcleo de } \\
\text { aprofundamento e } \\
\text { diversificação de } \\
\text { estudos das áreas } \\
\text { de atuação } \\
\text { profissional, } \\
\text { incluindo os } \\
\text { conteúdos } \\
\text { específicos e } \\
\text { pedagógicos }\end{array}$} & $\begin{array}{l}\text { Conteúdos } \\
\text { complementa- } \\
\text { res obrigatórios }\end{array}$ & $\begin{array}{c}\text { PCC } \\
\text { (20 créditos) }\end{array}$ & $\begin{array}{c}\text { Disciplina, } \\
\text { Seminário ou } \\
\text { Oficina (300 h/a) }\end{array}$ & $\begin{array}{c}\text { Depart. } \\
\text { Específico } \\
\text { e Departs. } \\
\text { do CE }\end{array}$ \\
\hline $\begin{array}{l}\text { INTERDISCIPLINAR } \\
\text { Prática como } \\
\text { Componente } \\
\text { Curricular - PCC }\end{array}$ & & $\begin{array}{l}\text { Conteúdos } \\
\text { complementa- } \\
\text { res optativos }\end{array}$ & $\begin{array}{c}\text { PCC } \\
\text { (8 créditos) }\end{array}$ & $\begin{array}{c}\text { Disciplina, } \\
\text { Seminário ou } \\
\text { Oficina (120 h/a) }\end{array}$ & $\begin{array}{l}\text { Depart. } \\
\text { Específico } \\
\text { e/ou vários } \\
\text { Departs. } \\
\text { da UFPB }\end{array}$ \\
\hline \multicolumn{3}{|c|}{ Total } & 28 Créditos & \multicolumn{2}{|c|}{$420 \mathrm{~h} / \mathrm{a}$} \\
\hline \multicolumn{3}{|c|}{ TOTAL GERAL } & 76 Créditos & \multicolumn{2}{|c|}{$1.140 \mathrm{~h} / \mathrm{a}$} \\
\hline
\end{tabular}

${ }^{*}$ CE - Centro de Educação; DFE - Departamento de Fundamentação da Educação; DHP - Departamento de Habilitações Pedagógicas; DME - Departamento de Metodologias da Educação. 


\section{autêntica}

DOI https://doi.org/10.31639/rbpfp.v\%vi\%i.196

- As disciplinas de caráter pedagógico e educacional, hoje consideradas como Prática como Componente Curricular, de caráter obrigatório e que totalizam 300 horas (indicadas no parágrafo $1^{\circ}$, incisos I, II e III do Art. 33 da Resolução CONSEPE/UFPB Nº. 16/2015), serão deslocadas para o eixo curricular dos conteúdos básicos profissionais (definidos no Inciso I, do parágrafo $2^{\circ}$ do Artigo 20 da Resolução CONSEPE/UFPB N. 16/2015). Nessa proposta, elas corresponderão aos conteúdos indicados no Inciso I, do artigo 12 das Diretrizes de 2015, os quais constituem o núcleo de estudos de formação geral, das áreas específicas e interdisciplinares, e do campo educacional, seus fundamentos e metodologias, e das diversas realidades educacionais.

- Aos conteúdos básicos profissionais, descritos acima, serão acrescentadas as 405 horas3 de Estágio Supervisionado, ofertadas pelo Departamento Específico ou pelo Departamento de Metodologia da Educação (DME/CE), totalizando uma carga horária de, no mínimo, 50\% (cinquenta por cento) da carga horária total do curso.

- Os Conteúdos complementares obrigatórios e complementares optativos (definidos no Inciso II, alíneas "a" e "b" do parágrafo $2^{\circ}$ do Artigo 20 da Resolução CONSEPE/UFPB No. 16/2015) corresponderão aos conteúdos indicados no Inciso II, do artigo 12 das Diretrizes de 2015, que constituem o núcleo de aprofundamento e diversificação de estudos das áreas de atuação profissional, incluindo os conteúdos específicos e pedagógicos, priorizadas pelo projeto pedagógico das instituições, em sintonia com os sistemas de ensino. A estes conteúdos serão acrescentadas as 420 horas da prática como componente curricular que podem ser ofertadas, integralmente, como componentes obrigatórios pelos Departamentos Específicos e, quando necessário, complementada pelo Centro ou Departamentos de Educação. Se o Departamento Específico entender necessário, pode flexibilizar 120h da carga horária total da Prática Curricular, de forma optativa e interdisciplinar, cuja oferta dos componentes fica à escolha do aluno em vários departamentos da universidade, desde que as Coordenações de Curso e/ou a Pró-Reitoria de Graduação regulamentem em resolução própria a validação da Prática Curricular Optativa para que esta atenda ao requisito de oportunizar ao aluno uma prática que produz algo no âmbito do ensino.

Nesse sentido, cabe lembrar, conforme assinalado antes, que a própria Resolução que instituiu as Diretrizes de 2015 já estabelece que os conhecimentos do campo educacional, seus fundamentos e metodologias, bem como das diversas realidades educacionais fazem parte do Núcleo de estudos de formação geral, das áreas específicas e interdisciplinares (Inciso I). As Diretrizes, igualmente, incluem os conteúdos pedagógicos, ao lado dos específicos, no Núcleo de aprofundamento e diversificação de estudos das áreas de atuação profissional (Inciso II).

Sem abrir mão de uma formação pedagógica geral que contempla os fundamentos multidisciplinares da Educação (que são deslocados para os conteúdos básicos profissionais obrigatórios), a oferta da PCC passa a ser, em grande parte (300h), de atribuição dos cursos de licenciatura, salvaguardando, no entanto, a possiblidade de colaborações com o Centro ou Departamentos de Educação, quando necessário. A outra parte (120h), de natureza interdisciplinar e optativa, pode ficar, a depender do entendimento e da regulamentação dos Departamentos Específicos, à escolha do aluno em vários departamentos da universidade, desde que o componente selecionado (Disciplina, Seminário ou Oficina), de fato, ao ser avaliado mediante regulamento das Coordenações de Curso atenda ao requisito de oportunizar ao aluno uma "prática que produz algo no âmbito do ensino" (BRASIL, 2001), ou seja, o conhecimento e a análise de situações pedagógicas, tais como: estudo de caso, estudo do meio, oficina de produção de material didático, experimentos e soluções de problemas didáticos, narrativas autobiográficas de docentes, uso de tecnologias educacionais entre outras estratégias de ensino-aprendizagem. 
DOI https://doi.org/10.31639/rbpfp.v\%vi\%i.196

\section{ENDNOTES}

1 Essa carga-horária superior às 400 horas obrigatórias definidas nas DCNs buscou atender ao sistema de equivalência de crédito por hora de aula adotado na instituição em que um crédito corresponde a quinze horas de aulas. Essa mesma lógica é seguida na definição da carga horária do estágio supervisionado.

2 Julgamos ser essa proposta mais adequada de que a opção de trabalhar a PCC, nas disciplinas específicas do curso, por meio do aumento da carga-horária reservada à "prática", quando esta, geralmente, é menor de que o restante do tempo destinado à teoria - a exemplo de uma disciplina de $90 \mathrm{~h}$ em que se destina $60 \mathrm{~h}$ para teoria e 30h para a prática, reproduzindo o velho modelo formativo que separa, primeiro, a teoria e, só depois, se "aplica" o conhecimento na prática.

3 Para os cursos de licenciatura cujos estágios são ofertados pelo Departamento de Metodologia da Educação (DME/CE), há resolução específica desse o Departamento que regulamenta a oferta de quatro estágios supervisionados de ensino, com carga-horária individual de 105h, totalizando 420h (Resolução DME/CE/ UFPB Nº. 01/2017).

\section{REFERÊNCIAS}

ANDRÉ, Marli (Org.). Práticas inovadoras na formação de professores. Campinas, SP: Papirus, 2016.

BARBOSA, Alessandro Tomaz. A Prática como Componente Curricular nos Projetos Pedagógicos dos Cursos de Licenciatura em Ciências Biológicas. In. X ANPED SUL, Florianópolis, outubro de 2014. Disponível em: <http://xanpedsul.faed.udesc.br/arq_pdf/1402-0.pdf> Acesso em: 22 mar. 2018

BRASIL. Lei n. 9.394, de 20 de dezembro de 1996. Estabelece as Diretrizes e Bases da Educação Nacional. Diário Oficial da União, Poder Legislativo, Brasília, DF, 23 dez 1996. p. 27833. Disponível em: <http://www. planalto.gov.br/ccivil_03/leis/I9394.htm> Acesso em: 5 jun. 2001.

BRASIL. Ministério da Educação. Conselho Nacional de Educação. Parecer CNE/CES 744/97. Fixa orientações para o cumprimento do Art. 65 da Lei n 9.394/96 (Prática de Ensino). Brasília: Ministério da Educação, 1997. Disponível em: <http://eprints.rclis.org/15280/1/manual_referencias_bibliograficas.pdf> Acesso em: 06 nov. 2018

Parecer CNE/CP N. 9/2001. Diretrizes Curriculares Nacionais para a Formação de Professores da Educação Básica, em nível superior, curso de licenciatura, de graduação plena. Brasília: Ministério da Educação, 2001a. Disponível em: <http://portal.mec.gov.br/cne/arquivos/pdf/009.pdf> Acesso em: 06 nov. 2018

Parecer CNE/CP 21/2001. Duração e carga horária dos cursos de Formação de Professores da Educação Básica, em nível superior, curso de licenciatura, de graduação plena. Brasília: Ministério da Educação, 2001 b. Disponível em: <http://portal.mec.gov.br/dmdocuments/cnecp_212001.pdf> Acesso em: 06 nov. 2018 


\section{autêntica}

DOI https://doi.org/10.31639/rbpfp.v\%vi\%i.196

Parecer CNE/CP No. 27/2001. Dá nova redação ao item 3.6, alínea c, do Parecer CNE/CP 9/2001, que dispõe sobre as Diretrizes Curriculares Nacionais para a Formação de Professores da Educação Básica, em nível superior, curso de licenciatura, de graduação plena. Brasília: Ministério da Educação, 2001 c. Disponível em: <http://portal.mec.gov.br/cne/arquivos/pdf/027.pdf> Acesso em: 06 nov. 2018

Parecer CNE/CP N²8/2001. Dá nova redação ao Parecer CNE/CP 21/2001, que estabelece a duração e a carga horária dos cursos de Formação de Professores da Educação Básica, em nível superior, curso de licenciatura, de graduação plena. Brasília: Ministério da Educação, 2001d. Disponível em: <http://portal.mec. gov.br/cne/arquivos/pdf/028.pdf> Acesso em: 28 nov. 2001

Resolução CNE/CP No. 1/2002. Institui as Diretrizes Curriculares Nacionais para a Formação de Professores da Educação Básica, em nível superior, curso de licenciatura, de graduação plena. Brasília: Ministério da Educação, 2002a. Disponível em: <http://portal.mec.gov.br/cne/arquivos/pdf/rcp01_02.pdf> Acesso em: 23 abr. 2002

Resolução CNE/CP N. 2/2002. Institui a duração e a carga horária dos cursos de licenciatura, de graduação plena, de Formação de Professores da Educação Básica, em nível superior. Brasília: Ministério da Educação, 2002b Disponível em: <http://portal.mec.gov.br/cne/arquivos/pdf/CP022002.pdf> Acesso em: 28 out. 2002

Parecer CNE/CES No. 15/2005. Solicitação de esclarecimento sobre as Resoluções CNE/CP N. 1/2002, que institui Diretrizes Curriculares Nacionais para a Formação de Professores da Educação Básica, em nível superior, curso de licenciatura, de graduação plena, e 2/2002, que institui a duração e a carga horária dos cursos de licenciatura, de graduação plena, de Formação de Professores da Educação Básica, em nível superior. Brasília: Ministério da Educação, 2005. Disponível em: <http://portal.mec.gov.br/cne/arquivos/pdf/ pces0015_05.pdf > Acesso: 16 nov. 2005

Parecer CNE/CP No. 2/2015. Diretrizes Curriculares Nacionais para a Formação Inicial e Continuada dos Profissionais do Magistério da Educação Básica. Brasília: Ministério da Educação, 2015a Disponível em: $<$ http://portal.mec.gov.br/index.php?option=com_docman\&view=download\&alias=17625-parecer-cne-cp-2-2015-aprovado-9-junho-2015\&category_slug=junho-2015-pdf\&ltemid=30192> Acesso em: 21 set. 2015

Resolução CNE/CP N. 2/2015. Institui as Diretrizes Curriculares Nacionais para a Formação Inicial e Continuada de Professores da Educação Básica, em nível superior, curso de licenciatura, de graduação plena. Brasília: Ministério da Educação, 2015b. Disponível em: <http://portal.mec.gov.br/secretaria-de-regulacao-e-supervisao-da-educacao-superior-seres/323-secretarias-112877938/orgaos-vinculados-82187207/21028-resolucoes-do-conselho-pleno-2015> Acesso em: 21 set. 2015

ESCARIÃO. Glória das Neves Dutra; NÁDER, Alexandre Antônio Gili. Recuperando a memória: o impacto da resolução CONSEPE 04/ 2004 na carga de ensino de graduação dos departamentos do CE. João Pessoa, 2004 (mimeo.).

GARCÍA, Carlos Marcelo. Formação de professores: para uma mudança educativa. Porto, Portugal: Porto Editora, 1999

LIBÂNEO, José Carlos; PIMENTA, Selma Garrido. Formação de profissionais da educação: visão crítica e perspectiva de mudança. Educação \& Sociedade, ano XX, n. 68, p. 239-277, dez.1999. 
NÓVOA, Antônio (Org.). Os professores e sua formação. Lisboa: Dom Quixote, 1992.

PIMENTA, Selma Garrido (Org.). Saberes pedagógicos e atividades docentes. 4. ed. São Paulo: Cortez, 2005.

UFPB. Universidade Federal da Paraíba. Conselho Superior de Ensino, Pesquisa e Extensão. Resolução CONSEPE/UFPB N $N^{0}$.04/2004. Estabelece a base curricular para a formação pedagógica dos cursos de Licenciatura da UFPB. João Pessoa: UFPB, 2004. Disponível em: <http://www.cchla.ufpb.br/ccl/contents/ documentos/res-consepe-04-2004_estabelece-a-base-curricular-para-a-formacao-pedagogica-dos-cursos-de-licenciatura.pdf> Acesso em: 20 nov. 2018

Resolução CONSEPE/UFPB N. 46/2012. Altera a Resolução CONSEPE/UFPB nº4/2004, que estabelece a base curricular para a formação pedagógica dos cursos de Licenciatura da UFPB. João Pessoa: UFPB, 2012. Disponível em: <https://sigrh.ufpb.br/sigrh/public/colegiados/filtro_busca.jsf> Acesso em: 21 set. 2017

Resolução CONSEPE/UFPB No. 16/2015. Aprova o Regulamento dos Cursos Regulares de Graduação da Universidade Federal da Paraíba. João Pessoa: UFPB, 2015. Disponível em: <https://sigrh.ufpb.br/sigrh/ public/colegiados/filtro_busca.jsf> 23 set. 2017

UFPB. Universidade Federal da Paraíba. Resolução №. 01/2017 - DME/CE/UFPB. Regulamenta os componentes curriculares obrigatórios de Estágio Supervisionado de Ensino cadastrados no Departamento de Metodologia da Educação e oferecidos aos cursos presenciais de licenciatura do Campus I da Universidade Federal da Paraíba. In: Boletim de Serviços, n. 54, p. 58-43, 28 set 2017. Disponível em: <https://sigaa.ufpb.br/sigaa/ public/departamento/noticias_desc.jsf?|c=pt_BR\&id=1385\&noticia=75525311> Acesso em: 02 nov. 2017

WEBER, Silke. Notas sobre o CNE e a qualidade do ensino superior. Educação e Sociedade, Campinas, v. 23, n. 80, p. $91-96,2002$. 
